Artvin Çoruh Üniversitesi

Orman Fakültesi Dergisi

ISSN:2146-1880, e-ISSN: 2146-698X

Yıl: 2018, Cilt: 19, Sayı:1, Sayfa: 39-47

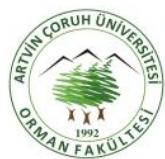

ofd.artvin.edu.tr
Artvin Coruh University

Journal of Forestry Faculty

ISSN:2146-1880, e-ISSN: 2146-698X

Year: 2018, Vol: 19, Issue: 1, Pages: 39-47

(c) (i)

\title{
Modifiye nanoselülozun kimyasal ve morfolojik analizi
}

\section{Chemical and morpholgical analysis of modified nanocellulose}

\author{
Bayram POYRAZ ${ }^{1}$, Recai ARSLAN ${ }^{2}$, Ahmet AKINCI ${ }^{2}$, Ayhan TOZLUOĞLU ${ }^{2}$ \\ ${ }^{1}$ Düzce Üniversitesi, Teknoloji Fakültesi, İnşaat Mühendisliği Bölümü, Düzce, Türkiye \\ ${ }^{2}$ Düzce Üniversitesi, Orman Fakültesi, Orman Endüstri Mühendisliği Bölümü, Düzce, Türkiye
}

\section{Eser Bilgisi / Article Info}

Araştırma makalesi / Research article

DOI: 10.17474 /artvinofd.342383

Sorumlu yazar / Corresponding author Ayhan Tozluoğlu

e-mail: ayhantozluoglu@duzce.edu.tr

ORCID: 0000-0002-1828-9450

Geliş tarihi / Received

09.10.2017

Düzeltme tarihi / Received in revised form

08.12.2018

Elektronik erişim / Online available

15.02.2018

Anahtar kelimeler:

Nanoselüloz

Modifikasyon

HPLC

FTIR

SEM

\section{Keywords:}

Nanocellulose

Modification

HPLC

FTIR

SEM

\begin{abstract}
Özet
Bu çalışmada, ökaliptus (Eucalyptus camaldulensis) odun yongalarından, ağartılmış kraft hamur lifi elde edilmiştir. Ardından ağartılmış hamur lifi 2,2,6,6-tetrametilpiperidin-N-oksil (TEMPO), Nhidroksiftalimit (PINO) ve periyodat (IO4-) ile modifiye edilmiştir. Sonrasında elde edilen ürünler homojenizatörden geçirilerek nano boyutlara düşürülmüş ve modifiye nanoseluloz elde edilmiştir. Elde edilen modifiye nanoselülozların, kimyasal özellikleri HPLC (High Performance Liquid Chromotography) ve FTIR (Fourier Transform Infrared) ile morfolojik analizleri ise SEM (Scanning Electron Microscopy) cihazları kullanılarak belirlenmiştir. Çalışmada modifikasyonlar sonrasında, moleküler ve amorf yapının değiştiği belirlenmiştir. Periyodat'ın, 2,2,6,6-tetrametilpiperidin- $\mathrm{N}$-oksil ve $\mathrm{N}$-hidroksiftalimit ile karşılaştırıldığında, glukoz üzerinde daha etkin olduğu belirlenmiştir. Morfolojik analizlerde 2,2,6,6-tetrametilpiperidin-N-oksil'in N-hidroksiftalimit'e ve periyodata oranla lif yapısının boyutsal değişiminde daha etkili olduğu gözlenmiştir. Son yıllarda nano seviyelerde yapılan çalışmaların sayısı giderek artış göstermektedir. Çalışmada nano boyutlara sahip nanoselüloz üretimi ve ardından üretilen nanoselülozun modifikasyonu başarıyla gerçekleştirilmiştir. Çalışma sonucunda modifiye nanoselülozların kimyasal ve morfolojik özellikler incelendiğinde, kullanılan kimyasalların nanoselüloz üzerinde farklı etkiler meydana getirdiği belirlenmiştir. Elde edilen bulgular ışığında mevcut çalışmanın literatüre destek sağlayacağı düşünülmektedir.
\end{abstract}

\begin{abstract}
In this this study, bleached kraft pulp fibers was obtained from Eucalyptus camaldulensis wood chips. Then, those bleached kraft pulp fibers were modified with 2,2,6,6-tetramethyl 1-1-piperidinyloxy (TEMPO), N-hydroxyphthalimide (PINO) and periodat $\left(\mathrm{IO}_{4}^{-}\right)$. Afterward, the obtained samples were passed through high pressure homogenizator to convert them to modified nanocellulose. Chemical and morpohlogical analysis of the obtained products were investigated by using HPLC (High Performance Liquid Chromotography), FTIR (Fourier Transform Infrared Spectroscopy) and SEM (Scanning Electron Microscopy) device. After modifications, it was determined that molecular and amorph structure altered the chemical structure of the samples. Periodate was more effective on glucose over to tetramethyl 1-1-piperidinyloxy and $\mathrm{N}$-hydroxyphthalimide. In the morphological analysis, 2,2,6,6-tetramethyl 1-1-piperidinyloxy caused more effective in that aspect of fibril structure. Studies regarding nano scale have been increased in the last years,. In the present study, nanocellulose productions and their modification were succesfully carried out. When investigated chemical and morphological properties of the obtained modified nanocellulose, it was determined that used chemicals led to different effects on the nanocellulose. In the light of the obtained data, it has been thought that the present study will make extra contribution to the literature.
\end{abstract}

\section{Giriş}

19.yy'da yaşanan sanayi devrimi, ardından otomotiv alanında yaşanan gelişmeler sonrasında ise 20.yy'da fizikte kuantum mekaniği kuramları ile birlikte bilgisayar teknolojisinde görülen gelişmeler endüstri ve sanayinin hızlı bir şekilde büyümesine neden olmuştur. Yaşanan bu gelişmeler ile birlikte insanoğlunun malzemeye olan ilgisi gittikçe artmıştır (Aydın 2007; Çapuroğlu 2002; Uysalman 2015).
İnsanoğlu son yıllarda nano boyutlarda imalatlara yönelme suretiyle nanoteknoloji ile tanışmıştır. Son yıllarda endüstriyel anlamda, çevreye duyarlı ve biyo çözünebilir olma özelliklerinden dolayı nanoselüloz polimeri büyük ilgi görmektedir (Güven ve ark. 2016).

Nanoselüloz lignoselülozik hammadde kaynaklarından elde edilebilen ve fiziksel, kimyasal ve morfolojik özellikleri sayesinde endüstriye olumlu etkiler kazandıran bir hammaddedir. Buna karşılık yaygın uygulama alanına sahip olan ve süreklilik arz eden biyokütleden nanoselüloz 
üretimi konusunda ülkemizde yeterli çalışma bulunmamaktadır (Yakkan 2015).

Nanoselüloz, liflendirilmiş nanoselüloz (CNF), kristal nanoselüloz (CNC) ve bakteriyel nanoselüloz (BNC) olmak üzere üç farklı türde bulunmaktadır. CNF, kimyasal veya enzimatik reaksiyonlar öncesi ve/veya sonrasında mekanik bir etki sonucu delaminasyonu ile oluşan, çapları 3-60 nm arasında, boylarının da birkaç $\mu$ m'ye kadar uzadığı türlerdir. CNC ise asit hidrolizi ile üretilen, $5-70 \mathrm{~nm}$ çapa, 100-250 nm aralığında değişen boylara sahip türlerdir. Bu iki türden ayrı olarak, bottom-up yöntemiyle üretilen BNC ise çapları 20-100 nm olan nanoselüloz tipleridir (Klemm ve ark. 2011). Bu nanoselüloz türleri içerisinde yüksek/en boy oranına ve uygun fiziksel özelliklere sahip, CNF ürünü malzeme üretiminde yoğun bir şekilde kullanılmaktadır (Lin ve Dufresne 2014).

CNF üretiminde, kullanılan hammadde, hemiselüloz ve lignin içeriği ile birlikte uygulanan kimyasal, enzim ve mekanik işlemlerin, elde edilen nanoselüloz'un fiziksel özellikleri üzerinde önemli etkileri bulunmaktadır. Farklı üretim metotlarına bağlı olarak elde edilen ürünler, benzer morfolojik özellikler gösterirken çap ve uzunluk gibi boyutsal özellikler açısından farklılıklar göstermektedir. Nakagaito ve Yano (2004), yaptıkları çalışmada kimyasal ön işlem uygulamadan homojenizatörden geçirdikleri nanoselüloz'un 20-40 nm çapa sahip olduğunu gözlemlerken, Iwamoto ve ark. (2007) ise öğütücüden geçirdikleri nanoselülozun 15-50 $\mathrm{nm}$ boyuta sahip olduğunu gözlemlemişlerdir. Saito ve ark. (2006) yaptıkları bir çalışmada 2,2,6,6tetrametilpiperidin-N-oksil modifikasyonu sonucu 3-5 nm çapa sahip nanoselüloz elde etmişlerdir. Leitner ve ark. (2007) ise karboksimetilasyon ve ardından yüksek basınçlı homojenizatör ile 10-15 nm'ye sahip nanoselüloz elde etmişlerdir. Ankerfors ve ark. (2009) ise enzimatik muamelenin ardından uygulanan homojenizasyon işlemi ile 20-30 nm lif boyutları gözlemlemişlerdir. Nanoselüloz üretiminde uygulanan işlemlerin, nihai ürünün özelliklerini etkilemesi ile birlikte selüloz, kimyasal yapısı itibariyle odunda, hemiselüloz ve lignin ile birlikte bulunmaktadır. Fakat hemiselülozlar ve ligninlerin selüloz nanofibrilleri arasındaki bağlantıyı engellediği için bu yapıların ağartma ile ortamdan uzaklaştırıması gerekmektedir (Alemdar ve Sain 2008; Lavoine ve ark. 2012).

Nanoselüloz kapsamlı özelliklere sahip olduğundan dolayı modifikasyonu üzerine pek çok çalışma yapılmaktadır. Modifikasyonlarda $\mathrm{H}_{2} \mathrm{SO}_{4}$ etkisiyle sülfat esterleri, açil klorürler ile ester, epoksiler ile eter, izosiyanatlar ile üretan, halojenli asetik asit ile karboksimetiller, kloro silanlar ile de oligomerik silanlı yapılar oluşturabilmek mümkün olmaktadır (Moon ve ark. 2011). Wei ve ark. (2017) kanola yağ asidi metil esteri ile nanoselülozu etkileştirerek termal kararlılığı ve hidrofobisitesini artırmıştır.

Kimyasal olarak bağlanma olabileceği gibi elektrostatik etkileşimler ile de modifikasyonlar gerçekleştirmek mümkün olmaktadır. Sülfolanmış nanoselülozun yüzeyi () yük ile yüklenirken, $(+)$ yüke sahip setiltetratraamonyum bromür ile ve yine $(+)$ yük'e sahip polietilen imin ile etkileşim sonucu elektrostatik etkileşim verebilmektedir (Moon ve ark. 2011).

$\mathrm{Bu}$ reaksiyonların selülozun modifikasyonunda polimerlerde kullanılmaktadır. Yi ve ark. (2008), CNC ile polistiren'den atom transfer radikal polimerleşmesi ile kopolimerin sıvı kristal özelliklerini incelemek amacıyla, nanoselülozu 2- bromoizobütirilbromür (başlatıcı) ile modifiye etmiştir.

Bu çalışmada, modifikasyonda kullanılan kimyasalların nanoselülozun fiziksel ve kimyasal özelliklerine etkileri üzerinde durulmuştur. Literatürde modifikasyon amacıyla en sık kullanılan kimyasal 2,2,6,6-tetrametilpiperidin-Noksil olmaktadır.

$\mathrm{Bu}$ çalışmada 2,2,6,6-tetrametilpiperidin- $\mathrm{N}$-oksil'nin yanında diğer modifikasyon ürünleri olan $\mathrm{N}$ hidroksiftalimit ve periyodat'ın, nanoselüloz üzerine etkileri, detaylı bir şekilde incelenmiştir. Elde edilen modifiye nanoselüloz örnekleri uygun koşullarda ve uygun proseslerde film üretiminde ve kompozit üretiminde uygulama potansiyeline sahiptir. Bununla birlikte modifiye nanoselüloz örneklerinin suspansiyonlar halinde gıda ve kozmetik sektöründe kullanım potansiyeline sahip olacağı düşünülmektedir. Ayrıca çalışmanın literatüre katkı sağlayacağı düşünülmektedir. 


\section{MATERYAL ve YÖNTEM}

\section{Hammadde Temini}

Çalışma kapsamında ana hammadde kaynağı olarak Avustralya'ya ait endemik bir ağaç türü olan okaliptüs (Eucalyptus camaldulensis) odunu kullanılmıştır. E. camaldulensis Mersin-Tarsus Orman İşletme Müdürlüğü Karabucak İşletme Şefliği'nde bulunan deneme alanından temin edilmiştir (Rakım: 5 metre, ağaç yaşı:16). Alınan tomruklar önce $3,5 \mathrm{~cm}$ kalınlığındaki disklere ayrılmış ve kabukları elle soyulduktan sonra örnekler 15-20 mm uzunluğunda, 1,5-2 mm kalınlığında ve 20-25 mm genişliğinde olacak şekilde bıçak yardımıyla yongalanmıştır. Yongalar hava kurusu hale getirildikten sonra rutubet miktarları belirlenerek her bir pişirme işlemi için $500 \mathrm{~g}$ (fırın kurusu) olacak şekilde yonga numuneleri paketlenmiştir.

\section{Ağartılmış Kraft Hamur Lifi Üretimi}

$\mathrm{Bu}$ amaç doğrultusunda $E$. camaldulensis odun yongalarından kraft metoduyla hamur üretimi sonrasında ağartma işlemi gerçekleştirilmiştir. Bu amaçla, ilk aşamada, elde edilen odun yongalarından $500 \mathrm{~g}$ alınmış ve 2,5 L ultra saf su (Purelab Flex, Elga) ilave edilmiştir (çözelti/yonga oranı 5/1). Ardından 1M $100 \mathrm{ml} \mathrm{NaOH}$ (Sigma Aldrich, Germany) ile 1,2 M $100 \mathrm{ml} \mathrm{Na} 2 \mathrm{SO}_{3}, 150$ ${ }^{\circ} \mathrm{C}$ 'de,150 dak. boyunca reaksiyon kazanında (Uniterm Rotary Digester,Uniterm Lab.) etkileştirilmiştir (Ayata 2008). Sonrasında 150 mesh'lik elek üzerinde saf su ile siyah çözelti uzaklaşıncaya kadar yıkanmış ve elenmiştir (disintegratör, elek açıklığı 0.15 mm ) (TAPPI T 275 sp-02). $\mathrm{Bu}$ şekilde liflenmeyen kısımlar ayrılmıştır. Pişirme aşamasından sonra elde edilen kraft hamur lifleri ECF (elementel chlorine free-klorsuz) ağartma işlemlerinden biri olan, ODEP (oksijen-klordioksit-alkali-peroksit)
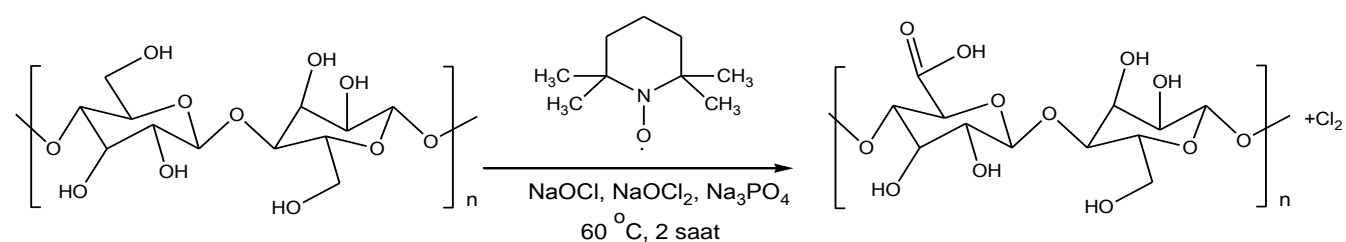

Şekil 1. Ağartılmış kraft hamur lifi ile 2,2,6,6-tetrametilpiperidin-N-oksil'in etkileşimi.

ağartma işlemine tabi tutulmuştur. Oksijen delignifikasyonu \%10 hamur yoğunluğu, \%2 NaOH (fırın kurusu hamur), \%0.5 $\mathrm{MgSO}_{4}$ (fırın kurusu hamur) ve $5 \mathrm{It}^{\prime}$ lik reaktör içerisinde $90{ }^{\circ} \mathrm{C}^{\prime}$ de 60 dak. boyunca $6 \mathrm{kgf} \mathrm{cm}-2$ basınçta gerçekleştirilmiştir. Klor dioksit ağartmasında ise (D) 10 g hamur (fırın kurusu) $100 \mathrm{~mL} \% 1 \mathrm{ClO}_{2}$ ve $3 \mathrm{~mL}$ $\mathrm{H}_{2} \mathrm{SO}_{4}$ (\%98) solüsyonuyla su banyosunda $60^{\circ} \mathrm{C}^{\prime}$ de 60 dak. muamele edilmiştir. Alkali ekstraksiyonu (E) kademesinde lifler $100 \mathrm{~mL} \% 2 \mathrm{NaOH}$ ile su banyosunda $60^{\circ} \mathrm{C}^{\prime}$ de 60 dak. muamele edilmiştir. Peroksit ağartma kademesi $(P)$ ise $\% 10$ hamur yoğunluğu, \%4 $\mathrm{H}_{2} \mathrm{O}_{2}$ (fırın kurusu hamur), $\% 1.5 \mathrm{NaOH}$ (fırın kurusu hamur), \%0.5 silika (fırın kurusu hamur), \%0.1 $\mathrm{MgSO}_{4}$ (fırın kurusu hamur) kullanılarak 5 It'lik reaktör içerisinde $105{ }^{\circ} C^{\prime}$ de $120 \mathrm{dk}$. süresince gerçekleştirilmiştir. Ağartma işlemi tamamlandıktan sonra lifler $100 \mathrm{~mL}$ saf su ile $60^{\circ} \mathrm{C}$ 'de 60 dak. süresince yıkanmış ve sonrasında distile su ile yıkama işlemine devam edilmiştir.

\section{Ağartılmış Kraft Hamur Liflerinin Modifikasyonu}

\section{Ağartılmış kraft hamur liflerinin 2,2,6,6- tetrametilpiperidin-n-oksil ile modifikasyonu}

Ağartılmış kraft hamur lifleri bu aşamada 2,2,6,6tetrametilpiperidin-N-oksil ile etkileştirilmiştir (Şekil 1). $\mathrm{Bu}$ amaçla $5 \mathrm{~g}$ fırın kurusu lif, $25 \mathrm{mg}$ 2,2,6,6tetrametilpiperidin-N-oksill ve $250 \mathrm{mg} \mathrm{NaBr}, 500$ mL'lik Na3PO4 tamponuna eklenmiş ve karışıma daha sonra $\mathrm{NaCl}(1,13 \mathrm{~g}, 10 \mathrm{mM})$ ve $\mathrm{NaClO}(1,13 \mathrm{~g}, 10 \mathrm{mM})$ eklenerek karışım çalkalamalı inkübatörde (GFL 3033) 150 rpm de 60 ${ }^{\circ} \mathrm{C}$ 'de 2 saat etkileştirilmiştir. İşlem süresince serbest klorun açığa çıkmasına bağlı olarak renk giderek sarıya dönmüş ve süre sonunda oksidasyon reaksiyonunu durdurmak için karışıma 100 mL etanol eklenerek karışım süzülmüş ve saf suyla yıkanmıştır. 


\section{Ağartılmış kraft hamur liflerinin $\mathrm{n}$-hidroksiftalimit ile modifikasyonu}

$\mathrm{Bu}$ işlemde $16 \mathrm{~g}$ fırın kurusu lif 1.4 It saf su-asetonitril karışımı (6:1), $3.2 \mathrm{mmol} \mathrm{AQ}$ (antrakinon), $3,2 \mathrm{mmol} \mathrm{O}_{2}$. N- hidroksiftalimit ile oda sıcaklığında 5 gün boyunca etkileştirilmiştir (Şekil 2). Sonrasında karışıma $100 \mathrm{~mL}$ etanol eklenerek reaksiyon durdurulmuştur. Elde edilen karışım süzülüp, saf su ve asetonla yıkanmıştır.
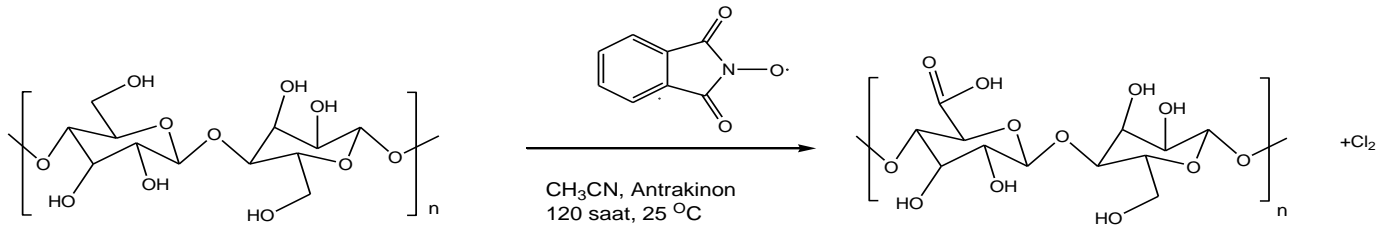

Şekil 2. Ağartılmış kraft hamur lifi ile N-hidroksiftalimit'in etkileşimi.

\section{Ağartılmış kraft hamur liflerinin periodat ile modifikasyonu}

Bu işlemde $4 \mathrm{~g}$ fırın kurusu lif $5.33 \mathrm{~g} \mathrm{NaIO} 4,15,6 \mathrm{~g} \mathrm{NaCl}$ ile $266 \mathrm{~mL}$ saf suya eklenmiş ve karışım oda sıcaklığında 105 rpm'de 4 gün süreyle GFL 3033 marka çalkalamalı inkübatörde muamele edilmiştir (Şekil 3). Reaksiyon
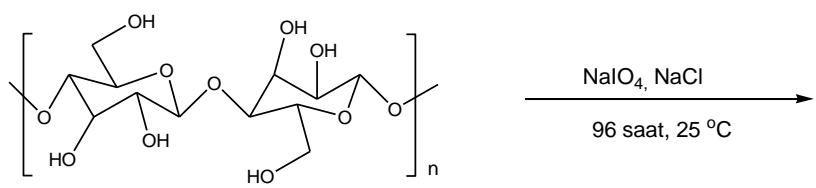

kabının dışı ışık girmesini engellemek için alüminyum folyo ile kaplanmıştır. 10, 16, 24 ve 96 . saatin sonunda karışımın 4'te $1^{\prime} \mathrm{i}$ alınıp yerine kalıntı periodatı uzaklaştırarak reaksiyonu sonlandırmak için gliserol eklenmiştir. 4 gün sonunda lifler süzülüp, saf suyla yıkanmıştır.

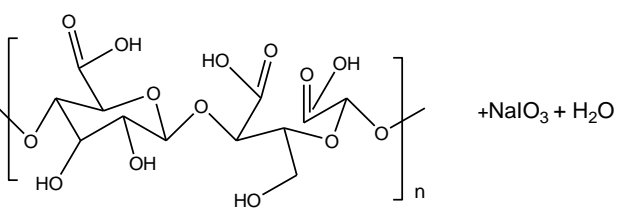

Şekil 3. Ağartılmış kraft hamur lifi ile periyodatın etkileşimi.

\section{Homojenizasyon (Fluidizing-Jelleştirme)}

$\mathrm{Bu}$ aşamada modifiye olmuş ve olmamış lifler fluidizer kullanılarak (M-110 Y, Microfluidics) nano boyuta indirgenmiştir. Çalışma kapsamında modifiye edilmemiş ağartılmış kraft hamur lifleri yüksek basınçlı homojenizatörden geçirilerek elde edilen nanoselüloz ürünü NC olarak isimlendirilmiş olup, ağartılmış kraft hamur lifinin 2,2,6,6-tetrametilpiperidin-N-oksil (TEMPO), $\mathrm{N}$-hidroksiftalimit (PINO) ve periyodat $\left(\mathrm{IO}_{4}^{-}\right)$ile modifiye edilmesi sonrası elde edilen liflerin yüksek basınçlı homojenizatörden geçirilmesi suretiyle elde edilen nanoselüloz ürünleri ise sırasıyla NC-T, NC-P ve NCI olarak isimlendirilmiştir. Bu bağlamda $\% 2 \mathrm{w} / \mathrm{w}$ konsantrasyonundaki lifler önce $200 \mu \mathrm{m}$ çapındaki odacıktan (1 döngü, 14000 psi) ardından $100 \mu \mathrm{m}$ (5 döngü, 24000 psi) çapındaki odacıklardan geçirilerek yukarıda bahsedilen nanoselüloz ürünlerinin üretimi gerçekleştirilmiştir.

\section{Analizler}

Çalışma kapsamında elde edilen tüm modifiye ve modifiyesiz nanoselüloz örneklerinin morfolojik (SEM) ve kimyasal (HPLC ve FTIR) özellikleri belirlenmiştir

HPLC (yüksek performanslı sıvı kromatografisi) analizleri Çalışma kapsamında elde edilen nanoselüloz numuneleri NREL (Laboratory Analytical Procedures (LAP) from the National Renewable Energy Laboratory) tarafından belirlenen yönteme göre hidroliz işlemine tabi tutulmuştur (Sluiter ve ark. 2004). HPLC analizleri RID (refractive index detector) detektör bağlı cihazda (Agilent 1200) $20 \mu \mathrm{L}$ enjeksiyon hacmi, mobil faz olarak ultra saf su ve $0.6 \mathrm{ml} / \mathrm{dk}$ akış hızında SHODEX SP 0810 kolonda 80 ${ }^{\circ} \mathrm{C}$ 'de yapılmıştır. Ayrıca hidroliz sonrası asitte çözünmeyen lignin içerikleri tartımla, asitte çözünen lignin içeriği ise $320 \mathrm{~nm}$ dalga boyunda saf suya karşı UV spektrofotometrede (Agilent) belirlenmiş olup her ikisinin toplamı toplam lignin olarak çalışma kapsamında sunulmuştur. 


\section{FTIR analizleri}

FTIR (Shimadzu, IR-Prestige 21) analizinde \%2 konsantrasyonlarda $0.5 \mathrm{ml}$ örnek alınmış ve ZnSe kristalinin üzerinde damlatılmıştır. Karakteristik moleküler absorpsiyon pikleri $4 \mathrm{~cm}^{-1}$ çözünürlüğünde ve 20 tarama sonucunda $600-4000 \mathrm{~cm}^{-1}$ aralığında bulunan bölgede belirlenmiştir.

\section{Morfolojik analizler}

Çalışmada SEM cihazı kullanılarak numunelerin morfolojik analizleri yapılmıştır (Quanta FEG250, FEI). Bu amaçla \%2 konsantrasyonlardaki örnekler $105{ }^{\circ} \mathrm{C}$ 'de 24 saat kurutulduktan sonra sputter cihazının kafesine yerleştirilerek, plazma ortamında yaklaşık $5 \mathrm{~nm}$ kalınlıkta gold-paladyum ile kaplanarak iletken hale getirilmiştir Sonrasında SEM cihazı içinde 1-15 kv arasında hızlandırma potansiyeline sahip bir voltajla, FEG tabancasından çıkan ışık ile etkileştirilerek secondary (ikincil) elektron dedektörü yardımıyla $1 \mu$ ve $100 \mu$ skalasında görüntüler alınmıştır.

\section{BULGULAR ve TARTIŞMA}

\section{Kimyasal Analizler}

\section{HPLC analizleri}

Çalışmada üretilen nanoselülozlara ait HPLC sonuçları Çizelge 1 ve 2'de verilmiştir.

Çizelge 1. Tüm aşamalar sonrasında elde edilen ürünlerin glukoz ve ksiloz miktarlarında meydana gelen \% değişimler.

\begin{tabular}{lcllllll}
\hline $\begin{array}{l}\text { Kimyasal } \\
\text { Bileşenler (\%) }\end{array}$ & Yonga & \multirow{2}{*}{ Kraft } & Ağartılmış Kraft & NC & NC-T & \multirow{2}{*}{ NC-P } & NC-I \\
\hline Glukoz & $40.0 \pm 1.53$ & $61.8 \pm 2.04$ & $66.3 \pm 0.90$ & $65.1 \pm 0.79$ & $53.0 \pm 0.92$ & $53.2 \pm 0.88$ & $51.0 \pm 0.81$ \\
Ksiloz & $8.67 \pm 0.19$ & $15.3 \pm 0.65$ & $14.3 \pm 0.85$ & $12.9 \pm 0.45$ & $3.54 \pm 0.49$ & $3.60 \pm 1.32$ & $4.10 \pm 0.93$ \\
\hline
\end{tabular}

Çizelge 2. Tüm aşamalar sonrasında elde edilen ürünlerin glukoz ve ksiloz miktarlarında meydana gelen kütlesel değişimler.

\begin{tabular}{llllllll}
\hline Tam kuru, g & Yonga & Kraft & $\begin{array}{l}\text { Ağartılmış } \\
\text { Kraft }\end{array}$ & NC & NC-T & NC-P & NC-I \\
\hline Toplam Hammadde & 500.0 & 228.0 & 207.5 & 206.8 & 203.6 & 201.3 & 176.2 \\
\hline Glukoz & 200.0 & 140.9 & 137.6 & 134.4 & 107.9 & 107.1 & 89.8 \\
\hline Ksiloz & 43.4 & 34.9 & 29.7 & 26.6 & 7.21 & 7.25 & 7.22 \\
\hline Toplam lignin & 141.7 & 6.90 & 3.00 & - & - & - & - \\
\hline
\end{tabular}

Çizelge 1 incelendiğinde modifikasyon işlemleri sonrası elde edilen nanoselülozların (NC-T, NC-P ve NC-I) glukoz ve ksiloz değerleri modifikasyonsuz nanoselüloza (NC) göre önemli ölçüde düşmüştür. Modifikasyon işlemleri kendi içinde incelendiğinde ise periyodat modifikasyonunun glukoz ve kslioz üzerinde 2,2,6,6tetrametilpiperidin-N-oksil, N-hidroksiftalimite oranla daha etkin olduğu gözlenmiştir.

Çizelge 2 incelendiğinde ise 2,2,6,6-tetrametilpiperidin- $N$ oksil, N-hidroksiftalimit ve periodat modifikasyonları sonrasında elde edilen NC-T, NC-P, NC-I ürünlerinin tam kuru yongaya oranla uzaklaşan glukoz ve ksiloz oranları sırasıyla \%46.1-83.4; \%46.5-83.3; \%55.1-83.3 olarak gözlenirken, modifikasyonlar sonrasında elde edilen nanoselülozlarda ağartılmış kraft hamuruna oranla uzaklaşan glukoz ve ksiloz oranları sırasıyla \%21.6-75.7; \%22.2-75.6 ve \%34.7-75.7 olarak gözlenmiştir. Modifikasyonsuz nanoselülozda ise bu oran \%2.33-10.4 olarak tespit edilmiştir.

\section{FTIR analizleri}

Modifikasyonlar sonucunda elde edilen NC, NC-T, NC-P ve NC-I numunelerine ait spektrumlar Şekil 4'de ve elde edilen titreşimler ise Çizelge 3 'te incelenmiştir. 


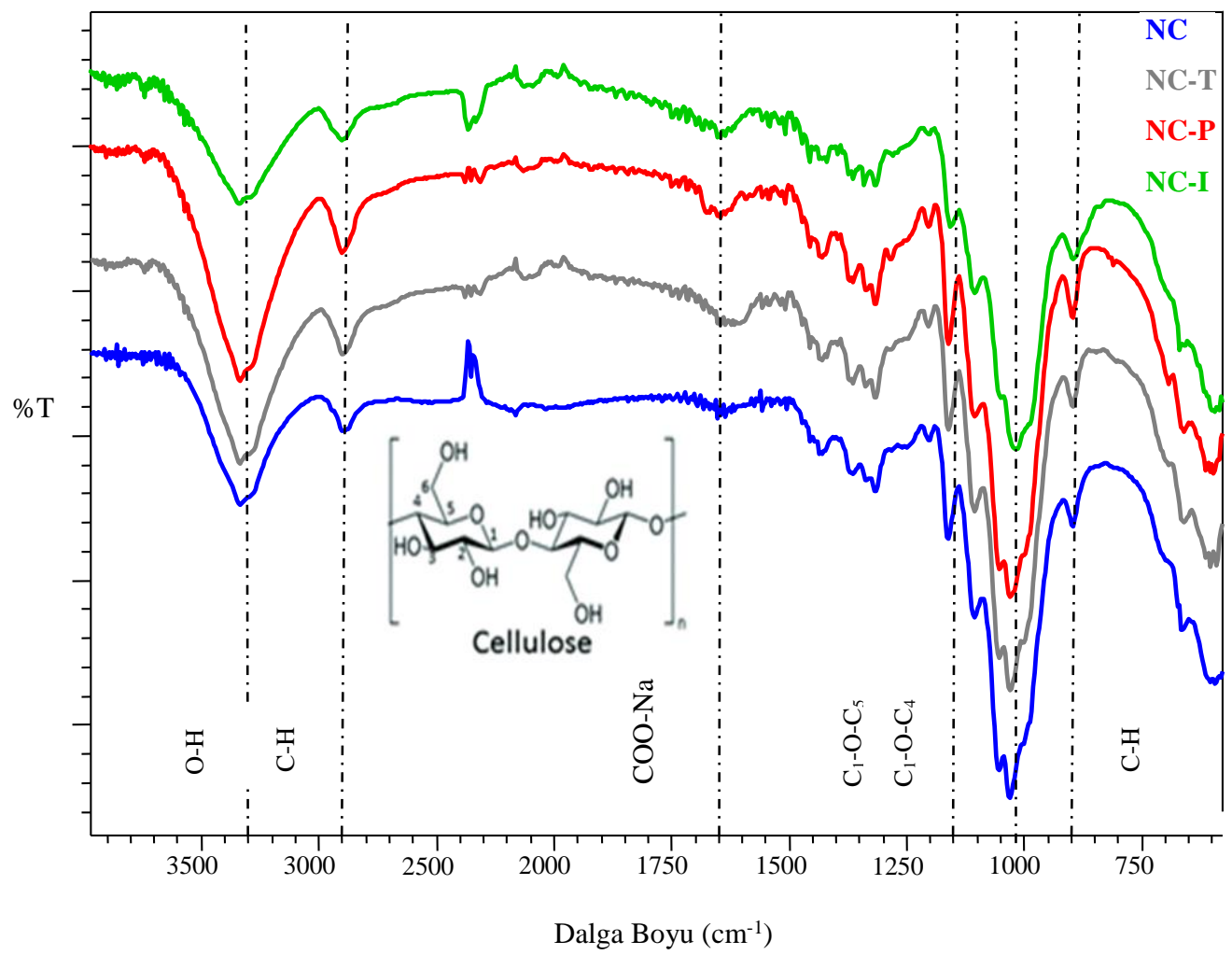

Şekil 4. NC, NC-T, NC-P ve NC-I için elde edilen FTIR spektrumları.

Çizelge 3. FTIR analizi sonrasında gözlenen titreşimler.

\begin{tabular}{lllllll}
\hline Madde/Titreşim(cm $\left.{ }^{-1}\right)$ & OH & CH & COO- & $\mathbf{C}_{\mathbf{1}}-\mathbf{O}-\mathbf{C}_{5}$ & $\mathbf{C}_{\mathbf{1}}-\mathbf{O}-\mathbf{C}_{4}$ & C-H \\
\hline NC & 3332 & 2902 & 1635 & $1161 ; 1105$ & $1053 ; 1028$ & 896 \\
NC-T & 3331 & 2897 & 1618 & $1161 ; 1105$ & $1051 ; 1029$ & 896 \\
NC-P & 3332 & 2897 & 1651 & $1161 ; 1105$ & $1051 ; 1029$ & 896 \\
NC-I & 3335 & 2900 & 1648 & $1157 ; 1105$ & $1049 ; 1016$ & 895 \\
\hline
\end{tabular}

Şekil 4'deki elde edilen titreşimler incelendiğinde, 2890 $\mathrm{cm}^{-1}$ 'de gözlenen metilen $\left(-\mathrm{CH}_{2}\right)$ gruplarına ait olan ve $-\mathrm{CH}$ asimetrik gerilme titreşimlerini veren etkileşimlerde değişimler gerçekleşmiştir. 2,2,6,6-tetrametilpiperidin- $\mathrm{N}$ oksil ve $\mathrm{N}$ hidroksi ftalimit, selüloz polimerini oluşturan sellebiyoz monomerlerinin birimlerinden olan anhidroglukoz molekülünün 6.C'nundaki primer hidroksil grubunu, 6.C'dan bir hidrojen koparmasıyla başlayan ve karbon merkezli bir hidroksimetil radikalinin oluşumuyla sonuçlanan süreç ile sodyum karboksilat grubuna dönüşmektedir. Selüloz zincirlerinin iki katlı gradyen eksen yapısı nedeniyle, sadece hidroksimetil grupları reaksiyona girmekte, diğer bölgeler kristalin bölge olduğundan bu bölgelerde reaksiyon gerçekleşmemektedir (Biliuta ve ark. 2011). Ayrıca ara ürün olan $\beta$ eliminasyonu sonucunda aldehit'te oluşabilmektedir. Bununla birlikte yan ürünler olarak $(1,4)$ $\beta$ glikozidik bağının radikaller tarafından koparıması sonucu depolimerizasyonda olabilmektedir (Hirota ve ark. 2009; Coseri ve ark. 2015). Selülozun periodat modifikasyonunda ise anhidroglukoz birimlerinin 2. C ve 3.C'daki komşu diolleri ayrılmaktadır ve reaksiyon siklik diesteri üzerinden ilerlemektedir. Bu durum sonucunda 2. $C$ ve 3.C'da aldehit grubuna sahip ürün oluşmaktadır (Kristiansen ve ark. 2010; Nikolic ve ark. 2011; Potthast ve ark. 2007). Bu oluşan durumlar sonucunda NC-I'nın amorfluğu daha fazla etkilenmiştir (Poyraz ve ark. 2017). Ayrıca, selülozu oluşturan sellebiyoz monomerlerinin birimlerinden, anhidroglukoz molekülleri arasındaki glikozidik bağı ifade eden $\mathrm{C}_{1}-\mathrm{O}-\mathrm{C}_{4}$ etkileşimi 
incelendiğinde, periyodat modifikasyonu sonrasında elde edilen NC-I'nın titreşim değerlerindeki değişim diğer modifikasyonlardaki elde edilen titreşimlerden daha fazla olmuştur. Bu titreşim değerlerindeki değişim, yukarıda açıklanan 2.C ve 3.C'nun etkilenmesinden kaynaklanmaktadır.

\section{Morfolojik Analizler}

Ağartılmış kraft hamur lifine ait SEM görüntüsü $100 \mu \mathrm{m}$ skalasında verilmiş olup, elde edilen NC, NC-T, NC-P, NC-I ürünlerinin SEM görüntüsü ise $1 \mu \mathrm{m}$ ve $100 \mu \mathrm{m}$ skalasında verilmiştir (Şekil 5).
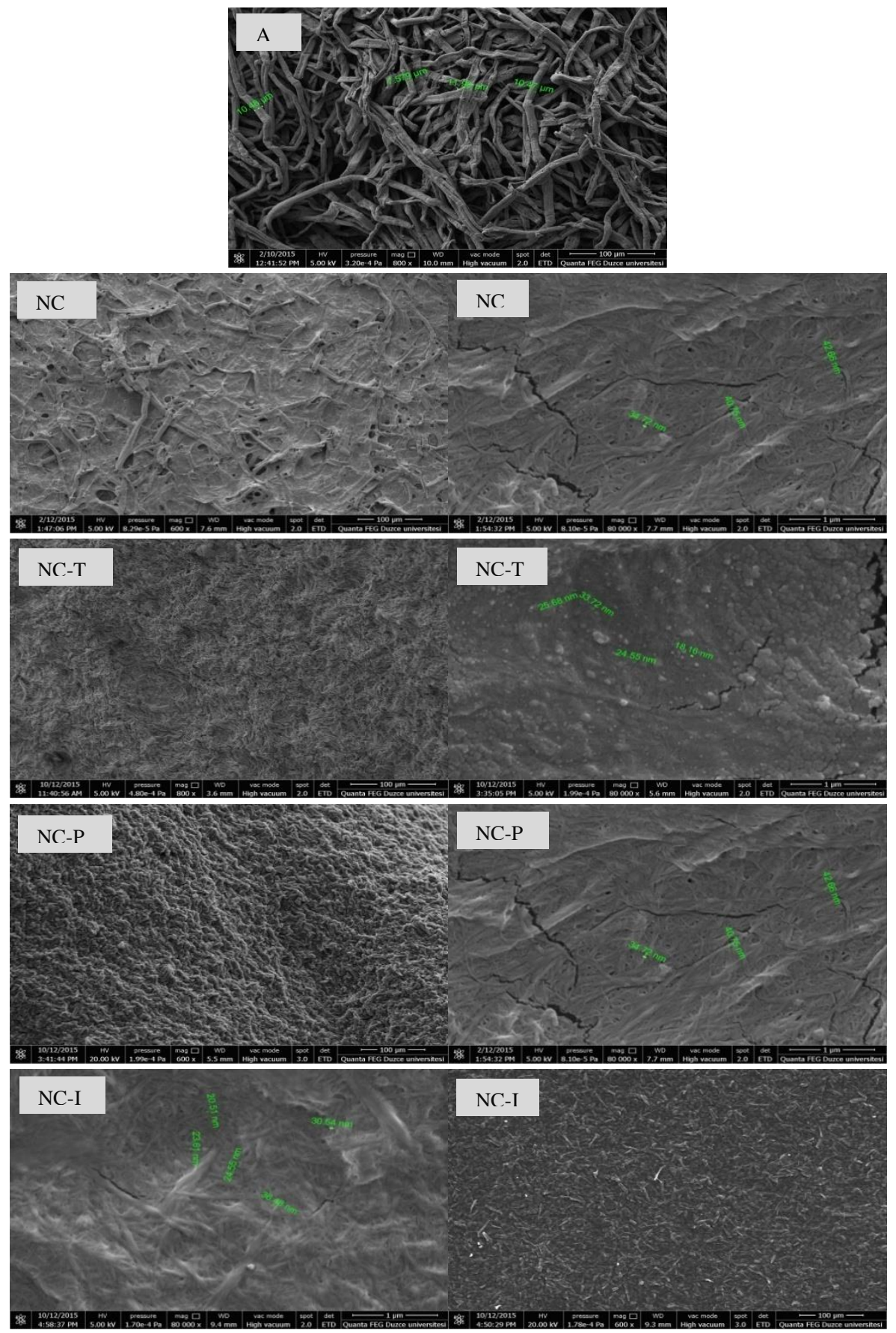

Şekil 5. Ağartılmış kraft hamur lifi (A) ve NC, NC-T, NC-P ve NC-I örneklerinin SEM görüntüleri

2,2,6,6-tetrametilpiperidin-N-oksil modifikasyonu sonrasında oluşan karboksilat grupları selüloz içerisindeki nanofibriller arasında itici kuvvetler oluşturmakta, liflerin su içerisinde daha kolay dağılarak homojenizasyon işlemi sırasında daha kolay modifiye nanoselüloz üretimine imkan tanımaktadır (Isogai ve ark. 2011). Bu nedenle, 
ağartışmış kraft hamur lifleri (A) ortalama $30 \mu \mathrm{m}$ çapında iken 2,2,6,6-tetrametilpiperidin-N-oksil etkisi sonrasında 20 nm'ye kadar düştüğü gözlenmiştir. Literatür çalışmalarında benzer sonuçların tespit edildiği görülürken, liflerin uzunluklarının ise modifikasyon koşullarına bağlı olarak değişim gösterdiği belirlenmiştir (Huang ve ark. 2015; Besbes ve ark. 2011).

$\mathrm{N}$-hidroksiftalimitin etkileşiminin sonucunda elde edilen görüntüler incelendiğinde, lif boyutları $40 \mathrm{~nm}$ 'lerde gözlenmiştir. $\mathrm{Bu}$ durumda $\mathrm{N}$-hidroksiftalimitin, lif boyutlarını küçültmede 2,2,6,6-tetrametilpiperidin-Noksil kadar etkili olmadığı belirlenmiştir. Periyodat etkisi sonucu elde edilen görüntüler incelendiğinde ise lif boyutlarının nitroksil radikalleri sonucu elde edilen lif boyutlarının, aralığında olduğu tespit edilmiştir. Ayrıca $100 \mu m^{\prime} l i k$ görüntüler incelendiğinde ise 2,2,6,6tetrametilpiperidin-N-oksilin selülozla daha etkin bir şekilde etkileştiği ve daha homojen hale getirdiği görülmüştür. Periyodat ise yapıda daha fazla deformasyon oluşturmuştur.

\section{SONUÇ}

Çalışmada ökaliptus odun yongalarından yararlanılarak ağartılmış kraft hamuru elde edilmiştir. Ağartılmış kraft hamuruna modifikasyonlar sonrasında selülozun modifikasyonu gerçekleştirilmiştir. Ardından elde edilen modifiye selüloz homojenizatörden geçirilerek modifiye nanoselüloz elde edilmiştir.

Çalışma sonucunda uygulanan HPLC analizlerinde periodatın, diğer radikal türlerine oranla glukoz üzerinde daha etkin olduğunu gözlenmiştir. Ksiloz üzerinde ise tüm modifikasyon işlemlerinin önemli bir değişim göstermediği belirlenmiştir.

FTIR analizleri sonucunda moleküller arası glikozidik bağı gösteren $\mathrm{C}_{1}-\mathrm{O}-\mathrm{C}_{4}$ bağında gözlenen kimyasal etkileşimlerin sonucu olarak NC-I numunesinin titreşim değerlerinde önemli değişimler gözlenmiştir. Fakat NC-T ve NC-P numunesinin titreşim değerlerinde değişim gözlenmemiştir. Bunun nedeni periyodatın $C_{2}$ ve $C_{3}$ karbonuna etki etmesi iken, 2,2,6,6 tetrametilpiperidin-1oksil ve $\mathrm{N}$-hidroksiftalimitin ise $\mathrm{C}_{6}$ karbonuna etki etmesinden kaynaklanmaktadır. Ayrıca modifikasyonlar sonucunda metilen gruplarına ait $\mathrm{CH}$ etkileşimlerinden dolayı kristal/amorf düzeninin değişimi gözlenmiştir.

SEM analizlerinde modifikasyon sonucunda liflerin yapısal değişimlerinde fiziksel değişimlerin meydana geldiği gözlenmiştir. 2,2,6,6 tetrametilpiperidin-1-oksil'in Nhidroksiftalimit'e ve periyodata oranla çok daha fazla etkili olduğunu ortaya koymuştur. Bununla birlikte homojenizasyon işleminden sonra lifsel yapının tamamen değiştiğini ve yüksek basınç altında gerçekleştirilen homojenizasyon neticesinde ürünlerin homojen bir şekilde nano boyuta indirgendiğini ortaya koymuştur.

\section{TEŞEKKÜR}

Bu çalışma TUBITAK COST 1140022 no'lu proje ile desteklenmiştir.

\section{KAYNAKLAR}

Alemdar A, Sain M (2008) Biocomposites from wheat straw nanofibers: Morphology, thermal and mechanical properties. Composites Science and Technology, 68(2): 557-565.

Ankerfors M, Lindström T, Henriksson G (2009) Method for the manufacture of microfibrillated cellulose. US Pat. 20090221812 A1.

Ayata $U$ (2008) A research of eucalyptus (Eucalyptus camaldulensis and Eucalyptus grandis) wood properties and their use in the paper industry. Master Thesis, Science Institute of Kahramanmaraş Sütçü İmam University, Kahramanmaraş, Turkey.

Aydın Z (2007) iletken poli(etilen teraftalat)/polipirol kompozit liflerinin kimyasal polimerizasyonla hazırlanması ve karakterizasyonu, Yüksek Lisans Tezi, Ankara Üniversitesi Fen Bilimleri Enstitüsü.

Bahar ER (2012) Selüloz nano parçacıklarıyla güçlendirilmiş polipropilen nanokompozit malzemelerin solvent casting metodu ile hazırlanması ve analizi, Yüksek Lisans Tezi, İstanbul Teknik Üniversitesi, Fen Bilimleri Enstitüsü.

Besbes I, Alila S, Boufi S (2011) Nanofibrillated cellulose from TEMPOoxidized eucalyptus fibres: Effect of the carboxyl content. Carbohydrate Polymers, 84: 975-983.

Biliuta G, Fras L, Harabagiu V, Coseri S (2011) Mild oxidation of cellulose fibers using dioxygen as ultimate oxidizing agent. Digest Journal of Nanomaterials and Biostructures, 6(1): 291- 297.

Çapuroğlu M, (2002) Effect of ionizing radiation on the stability of carbon black filled ethylene vinyl acetate copolymer, Yüksek Lisans Tezi, Hacettepe University, Fen Bilimleri Enstitüsü.

Coseri S, Biliuta G, Zemljič LF, Srndovic JS, Larsson PT, Strnad S, Kreže T, Naderi A, Lindström R (2015) One-shot carboxylation of microcrystalline cellulose in the presence of nitroxyl radicals and sodium periodate. RSC Advances, 5(117): 85889-85897.

Güven O, Monteiro SN, Mourac EAB, Drelich JW (2016) Re-emerging field of lignocellulosic fiber - Polymer composites and ionizing radiation technology in their formulation. Polymer Reviews, 56(4): 702-736. 
Hirota M, Tamura N, Saito T, Isogai A (2009) Oxidation of regenerated cellulose with $\mathrm{NaClO}_{2}$ catalyzed by TEMPO and $\mathrm{NaClO}$ under acidneutral conditions. Carbohydrate Polymers, 78: 330-335.

Huang C-F, Chen J-K, Tsai T-Y, Hsieh Y-A, Lin K-Y A (2015) Dualfunctionalized cellulose nanofibrils prepared through TEMPO mediated oxidation and surface-initiated ATRP. Polymer, 72: 395405.

Isogai A, Saito T, Fukuzumi H (2011) TEMPO oxidized cellulose nanofibers. Nanoscale, 3: 71-85.

Iwamoto S, Nakagaito AN, Yano H (2007) Nano-fibrillation of pulp fibers for the processing of transparent nanocomposites. Applied Physics A, 89(2): 461-466.

Klemm D, Kramer F, Moritz S, Lindström T, Ankerfors M, Gray D, Dorris A (2011) Nanocelluloses: A new family of nature-based materials. Angewandte Chemie International Edition, 50(24): 5438-5466.

Kristiansen KA, Potthast A, Christensen BE (2010) Periodate oxidation of polysaccharides for modification of chemical and physical properties. Carbohydrate Research, 345: 1264-1271.

Lavoine N, Desloges I, Dufresne A, Bras J (2012) Microfibrillated cellulose-Its barrier properties and applications in cellulosic materials: A review. Carbohydrate Polymers, 90(2): 735-764.

Leitner J, Hinterstoisser B, Wastyn M, Keckes J, Gindl W (2007) Sugar beet cellulose nanofibril-reinforced composites. Cellulose, 14(5): 419-25.

Lin N, Dufresne A (2014) Nanocellulose in biomedicine: Current status and futureprospect. European Polymer Journal, 59: 302-325.

Moon RJ, Martini A, Nairn J, Simonsen J, Youngblood J (2011) Cellulose nanomaterials review: Structure, properties and nanocomposites. Chemical Society Reviews, 40(7): 3941-94.

Nakagaito AN, Yano H (2004) The effect of morphological changes from pulp fiber towards nano-scale fibrillated cellulose on the mechanical properties of highstrength plant fiber based composites. Applied Physics A, 78(4): 547-552.
Nikolic T, Kostic M, Praskal J, Petronijevic Ž, Škundrič P (2011) Sorption properties of periodate oxidized cotton. Chemical Industry \& Chemical Engineering Quarterly, 17(3): 367-374.

Potthast A, Kostic M, Schiehser S, Kosma P, Rosenau T (2007) Studies on oxidative modifications of cellulose in the periodate system: Molecular weight distribution and carbonyl group profiles. Holzforschung, 61: 662-667.

Poyraz B, Tozluoglu A, Candan Z, Demir A, Yavuz M (2017) Influence of PVA and silica on chemical, thermo-mechanical and electrical properties of Celluclast-treated nanofibrillated cellulose composites. International Journal of Biological Macromolecules, 104(Pt A): 384-392.

Saito T, Nishiyama Y, Putaux JL, Vignon M, Isogai A (2006) Homogeneous suspensions of individualized microfibrils from TEMPO-catalyzed oxidation of native cellulose. Biomacromolecules, 7(6): 1687-1691.

Sluiter A, Hames B, Ruiz R, Scarlata C, Sluiter J, Templeton D (2004) NREL biomass program: Determination of structural carbohydrates and lignin in biomass, Biomass Analysis Technology Team, Laboratory Analytical Procedure 2004, Department of Energy, United States of America.

Uysalman T, (2015) Çevreye duyarlı yüksek mukavemetli polipropilen lignin kompozitleri, Yüksek Lisans Tezi, İmir Katip Çelebi Üniversitesi, Malzeme Bilimi ve Mühendisliği.

Wei L, Agarwal UP, Hirth KC, Matuana LM, Sabo RC, Stark NM (2017) Chemical modification of nanocellulose with canola oil fatty acid methyl ester. Carbohydrate Polymers, 169: 108-116.

Yakkan E, (2015) Nanocellulose-Propilen Kompozitler, Yüksek Lisans Tezi, İzmir Katip Çelebi Üniversitesi, Malzeme Bilimi ve Mühendisliği.

Yi J, Xu Q, Zhang X, Zhang $H$ (2008) Chiral-nematic self-ordering of rodlike cellulose nanocrystals grafted with poly(styrene) in both thermotropic and lyotropic states. Polymer, 49(20): 4406-4412. 